\title{
PENGAWASAN OTORITAS JASA KEUANGAN (OJK) TERHADAP PERBANKAN SEBAGAI UPAYA PERLINDUNGAN HUKUM NASABAH ATAS PENJUALAN DATA NASABAH BANK \\ Oleh: Emma Sandi ${ }^{1}$
}

\begin{abstract}
This study raised the issue of customer legal protection for the sale of bank customer data and OJK supervision of the obligation of confidentiality on the sale of bank customer data. This research was conducted to analyze the legal protection of customers for the sale of bank customer data and analyze OJK supervision of the obligation of confidentiality on the sale of bank customer data.

This thesis uses normative legal research because it focuses on library research which essentially examines legal principles, systematic law, and synchronizes the law by analyzing it. The data obtained were analyzed using qualitative normative methods.

The results of the study found that customer legal protection for the sale of bank customer data can be said that the legal protection has been covered by the existence of SEOJK Number 14 of 2014 Concerning the Confidentiality and Security of Data and / or Consumer Personal Information, and POJK Number 1 of 2013 Concerning Service Sector Consumer Protection Finance. OJK's oversight of the obligations of secrecy over the sale of bank customer data in this case is seen from the market conduct supervision of banking financial services by the OJK, as a whole has been carried out by the OJK Office, but has not been fully implemented by OJK in the regions / OJK districts / cities.

Keywords: Customer Legal Protection, Confidential Bank Customer Data, OJK Supervision
\end{abstract}

\section{ABSTRAK}

Penelitian ini mengangkat permasalahan perlindungan hukum nasabah atas penjualan data nasabah bank dan pengawasan OJK terhadap kewajiban kerahasiaan atas penjualan data nasabah bank. Penelitian ini dilakukan untuk menganalisis perlindungan hukum nasabah atas penjualan data nasabah bank dan menganalisis pengawasan OJK terhadap kewajiban kerahasiaan atas penjualan data nasabah bank.

Tesis ini menggunakan penelitian hukum normatif karena menitikberatkan pada penelitian kepustakaan yang intinya meneliti asas-asas hukum, sistematis hukum, dan sinkronisasi hukum dengan cara menganalisanya. Data yang diperoleh dianalisis dengan menggunakan metode normatif kualitatif.

Hasil penelitian menemukan bahwa Perlindungan hukum nasabah atas penjualan data nasabah bank dapat dikatakan bahwa perlindungan hukum tersebut sudah diatur dengan adanya SEOJK Nomor 14 Tahun 2014 Tentang Kerahasiaan dan Keamanan Data dan/atau Informasi Pribadi Konsumen, dan POJK Nomor 1 Tahun 2013 Tentang Perlindungan Konsumen Sektor Jasa Keuangan. Pelaksanaan pengawasan OJK terhadap kewajiban kerahasiaan atas penjualan data nasabah bank dalam hal ini dilihat dari sisi pengawasan market conduct jasa keuangan perbankan oleh OJK, secara keseluruhan sudah dilaksanakan oleh Kantor OJK, namun belum dilaksanakan sepenuhnya oleh OJK di wilayah/daerah seperti OJK kabupaten/kota.

Kata kunci: Perlindungan Hukum Nasabah, Rahasia Data Nasabah Bank, Pengawasan OJK

\footnotetext{
${ }^{1}$ Pegawai BUMD Bank Jateng Syariah
} 
1533 | Jurna I I d e a H u k u m

Vol. 5 No. 2 Oktober 2019

MagisterIImuHukum Universitas Jenderalsoedirman

\section{A. Pendahuluan}

Lembaga perbankan sebagai salah satu bentuk lembaga keuangan merupakan inti dari sistem keuangan dari setiap negara, karena ia merupakan lembaga keuangan yang mempunyai kedudukan sangat penting dalam kehidupan perekonomian. Ketentuan Pasal 1 angka 2 Undang-undang Nomor 10 Tahun 1998 Tentang Perbankan menyatakan bahwa bank adalah badan usaha yang menghimpun dana masyarakat dalam bentuk simpanan dan menyalurkannya kepada masyarakat dalam bentuk kredit dan atau bentuk-bentuk lainnya dalam rangka meningkatkan taraf hidup orang banyak. Pelaksanaan kegiatan usaha bank secara umum adalah pengumpulan dana, pemberian kredit, mempermudah sistem pembayaran dan penagihan, serta pemberian jasa keuangan lainnya. $^{2}$ Pengguna jasa lembaga perbankan disebut nasabah. Kegiatan perbankan dalam melayani nasabah ini dilakukan oleh pegawai bank.

Dalam dunia perbankan, pegawai bank merupakan perantara antara bank dengan nasabahnya, karena yang berhubungan langsung untuk mengurus dan menjalankan

2 Muhammad Djumhana. 2000. Hukum Perbankan Di Indonesia. Bandung: CV.Mandar Maju. HIm.140. transaksi keuangan nasabah adalah pegawai bank. Oleh karena itu pegawai bank sangat rentan untuk melakukan tindakan kejahatan seperti penjualan data nasabah. Guna menghindari terjadinya penyalahgunaan data dan keuangan nasabah maka dibuatlah peraturan khusus yang melarang bank untuk memberikan informasi tercatat kepada siapapun berkaitan dengan data termasuk keadaan keuangan nasabah, simpanan dan penyimpanannya sebagaimana diatur dalam Pasal 1 angka 28 UU Perbankan yang menyebutkan bahwa rahasia bank adalah segala sesuatu yang berhubungan dengan keterangan mengenai nasabah penyimpan dan simpanannya.

Walaupun pola dan perilaku pegawai bank dalam menjalankan tugasnya telah diatur, namun saat ini, masih terjadi penyimpanganpenyimpangan yang dilakukan oleh pegawai bank atau mantan pegawai bank. Bank yang seharusnya mengelola bisnis dengan kepercayaan telah banyak disalahgunakan oleh para pegawai bank yang dapat menimbulkan kerugian, baik bagi nasabah, pegawai bank itu sendiri, maupun bank yang bersangkutan.

Praktek penjualan atau jual beli data nasabah akhir-akhir ini semakin banyak terjadi, seperti yang 


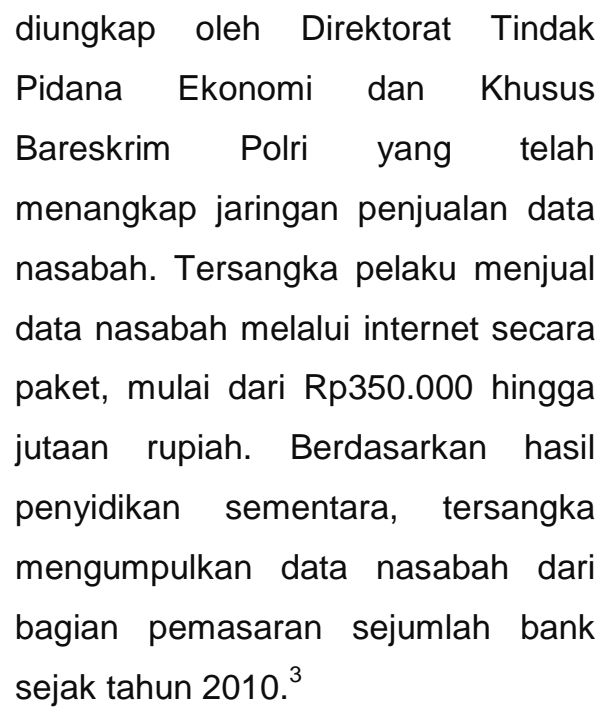
Menurut Otoritas Jasa Keuangan (OJK) yang selama ini melakukan pemantauan interaksi antara Pelaku Usaha Jasa Keuangan dengan konsumen keuangan dan masyarakat, jual beli data nasabah perbankan masih marak dilakukan. OJK sudah sejak tahun lalu melakukan market intelligence untuk mengungkap kasus dari sisi industri keuangan, dan menemukan adanya kasus penjualan data nasabah yang akan ditindak lanjuti oleh Direktorat Investigasi. Padahal sesuai dengan Surat Edaran Otoritas Jasa Keuangan Nomor 14/SEOJK.07/2014 Tentang Kerahasiaan dan Keamanan Data dan/ atau Informasi Pribadi Konsumen, PUJK dilarang memberikan informasi data nasabah

${ }^{3}$ Juli Etha Manalu, Agne Yasa Damanik, \& Andry Winanto. 2017. Kasus Jual-Beli Informasi Nasabah : Lindungi Data Pribadi !. Tribun Jateng. 22 Agustus 2017. kepada pihak ketiga. ${ }^{4}$ Sesuai dengan peraturan yang berlaku di bank, data pribadi tidak boleh diperjualbelikan atau diberikan kepada pihak lain tanpa persetujuan orang yang bersangkutan.

Fakta adanya kasus jual beli data nasabah yang dilakukan oleh oknum pegawai bank seperti yang diungkap di atas, mengindikasikan bahwa peraturan perbankan yang mengatur kerahasiaan data nasabah bank dan perlindungan hukum nasabah dalam kegiatan perbankan yang saat ini berlaku, belum mampu mencegah terjadinya kejahatan di dunia perbankan yang sangat merugikan pihak nasabah. Dengan demikian maka patut dipertanyakan bagaimana pengawasan OJK pada perbankan yang selama ini sudah berjalan sebagai upaya perlindungan hukum bagi nasabah bank.

Pengawasan yang dilakukan oleh OJK pada lembaga jasa keuangan meliputi 2 macam yaitu pengawasan prudential dan pengawasan market conduct. Pengawasan Market conduct merupakan bagian dari aturan dan pengawasan terhadap lembaga keuangan yang fokus kepada perilaku penyimpangan dan penyalahgunaan kekuasaan dalam penyertaan informasi yang bertujuan untuk memastikan bahwa lembaga

${ }^{4}$ Ibid. 
1535 | Jurna I I d e a H u k u m

Vol. 5 No. 2 Oktober 2019

MagisterIImuHukum Universitas Jenderalsoedirman

keuangan memberikan pelayanan yang baik dan jujur kepada konsumen. $^{5} \quad$ Terkait dengan kerahasiaan data nasabah bank agar tidak terjadi kebocoran informasi, maka OJK perlu meningkatkan framework pengawasan market conduct dengan memperkuat kemampuan tenaga pengawas khusus di market conduct di seluruh cabang di daerah.

Berdasarkan hal tersebut maka penulis merasa perlu melakukan penelitian untuk mengkaji pengawasan yang dilakukan oleh OJK terhadap kegiatan perbankan untuk mengantisipasi kejahatan di dunia perbankan khususnya tentang penjualan data nasabah, dengan mengangkat judul: "Pengawasan Otoritas Jasa Keuangan (OJK) Terhadap Perbankan Sebagai Upaya Perlindungan Hukum Nasabah Atas Penjualan Data Nasabah Bank".

\section{B. Perumusan Masalah}

1. Bagaimanakah perlindungan hukum nasabah atas penjualan data nasabah bank?

2. Bagaimana pengawasan OJK terhadap kewajiban kerahasiaan atas penjualan data nasabah bank?

${ }^{5}$ Muliaman D Hadad. 2014. OJK Perkuat Perlindungan Konsumen Melalui Pengawasan Market Conduct. Siaran Pers: No. SP-25/DKNS/OJK/9/2014.
C. Metode Penelitian

Jenis penelitian yang digunakan dalam penelitian ini adalah penelitian hukum normatif atau normative legal research, yaitu penelitian yang mengkonsepkan hukum sebagai apa yang tertulis dalam peraturan perundangundangan atau laws in book atau hukum dikonsepkan sebagai kaidah atau norma yang merupakan patokan berperilaku manusia yang dianggap pantas. ${ }^{6}$ Metode pendekatan yang digunakan dalam penelitian ini adalah pendekatan perundangundangan atau statue approach, yaitu pendekatan penelitian yang dilakukan dengan menelaah semua undang-undang dan regulasi yang bersangkut paut dengan isu hukum yang sedang ditangani. ${ }^{7}$ Data yang digunakan dalam penelitian ini menggunakan data sekunder dan data primer. Pengumpulan data sekunder dilakukan dengan melakukan studi kepustakaan dan studi dokumenter. ${ }^{8}$ Metode analisis data yang digunakan dalam penelitian ini adalah metode analisis data normatif kualitatif, yaitu analisis

\footnotetext{
6 Amiruddin dan Zainal Asikin. 2006. Pengantar Metode Penelitian Hukum. Jakarta: PT. Raja Grafindo Persada. HIm.118.

7 Peter Mahmud Marzuki. 2008. Penelitian Hukum (Cetakan ke 2). Jakarta :Kencana. HIm.29.

8 Saryono Hanadi. 2008. Metodologi Penulisan dan Penelitian Hukum. Purwokerto : Universitas Jenderal Soedirman. HIm.9.
} 
data yang menggunakan cara berpikir secara konstruksi logis konsisten yang mana terdapat cara berpikir yang dibangun berdasarkan hukum-hukum logika ilmiah (berpikir ilmiah) untuk menerjemahkan suatu data atau menjabarkan serta menafsirkan hubungan antara fakta yang satu dengan fakta yang lain. ${ }^{9}$

\section{Hasil dan Pembahasan}

\section{Perlindungan Hukum Nasabah} Atas Penjualan Data Nasabah Bank

Pada Peraturan Pemerintah

Republik Indonesia Nomor 2 Tahun 2002 Tentang Tata Cara Perlindungan Korban dan Saksi Dalam Pelanggaran Hak Asasi Manusia Yang Berat menyebutkan bahwa perlindungan hukum adalah suatu perlindungan yang diberikan kepada subyek hukum sesuai dengan aturan hukum, baik itu yang bersifat preventif (pencegahan) maupun dalam bentuk yang bersifat represif (pemaksaan), baik yang secara tertulis maupun tidak tertulis dalam rangka menegakkan peraturan hukum.

Ditemukannya kasus praktek penjualan atau jual beli data nasabah seperti yang diungkap oleh Direktorat Tindak

${ }^{9}$ Trusto Subekti. 2009. Metodologi Penulisan dan Penelitian Hukum. Purwokerto: Universitas Jenderal Soedirman. HIm.100.
Pidana Ekonomi dan Khusus Bareskrim Polri, di mana pelaku menjual data nasabah melalui internet secara paket $^{10}$ menjadi bukti nyata adanya tindak kejahatan di dunia perbankan khususnya adalah jual beli data nasabah yang sangat merugikan pihak nasabah. Berdasarkan bukti ini, maka ada masalah dalam rahasia bank terkait keamanan data nasabah atau konsumen bank sehingga perlindungan hukum bagi nasabah sangat diperlukan.

\begin{tabular}{lcr}
\multicolumn{1}{r}{ Salah } & satu tujuan dari \\
dibuatnya & Otoritas Jasa \\
Keuangan & (OJK) & adalah untuk \\
melindungi & \multicolumn{3}{c}{ kepentingan } \\
konsumen di sektor jasa
\end{tabular}
keuangan. Apabila sudah terjadi tindak pemberian informasi atau data konsumen kepada pihak lain seperti penjualan data untuk keuntungan pegawai bank sendiri, maka nasabah dapat membuat pengaduan baik kepada pihak bank sendiri atau pun kepada pihak OJK. Apabila nasabah membuat pengaduan kepada OJK, maka pihak OJK akan melakukan pembelaan hukum dari memerintahkan kepada PUJK untuk menyelesaikan pengaduan

10 Juli Etha Manalu, Agne Yasa Damanik, \& Andry Winanto. 2017. Kasus Jual-Beli Informasi Nasabah : Lindungi Data Pribadi !. Tribun Jateng. 22 Agustus 2017. 
1537 | Jurna I I d e a H u k u m

Vol. 5 No. 2 Oktober 2019

MagisterIImuHukum Universitas Jenderalsoedirman

konsumen yang dirugikan hingga pengajuan gugatan jika pihak PUJK tidak menyelesaikan pengaduan konsumen.

Perlindungan hukum secara preventif diatur dalam POJK Nomor 1 Tahun 2013 yaitu PUJK wajib untuk mencegah pengurus, pengawas, dan pegawainya dari perilaku memperkaya atau menguntungkan diri sendiri atau pihak lain, menyalahgunakan kewenangan, kesempatan, atau sarana yang ada padanya karena jabatan atau kedudukannya, yang dapat merugikan Konsumen dan PUJK dilarang dengan cara apapun, memberikan data dan/atau informasi mengenai konsumennya kepada pihak ketiga kecuali dengan persetujuan tertulis dari konsumen. Perlindungan hukum nasabah mendapat hak-haknya antara lain nasabah mempunyai hak untuk mendapatkan kenyamanan atas pelayanan yang diberikan oleh bank, mempunyai kebebasan untuk memilih produk/ layanan yang disediakan oleh bank, mempunyai hak untuk mendapatkan informasi yang benar dan jelas mengenai manfaat/ kelebihan termasuk kekurangan produk/ layanan yang ditawarkan oleh bank, mempunyai hak untuk mendapat tanda bukti kepemilikan produk dan/atau pemanfaatan layanan kepada konsumen tepat pada waktunya sesuai dengan perjanjian, mempunyai hak untuk mendapatkan perlindungan, yaitu bank wajib menjaga keamanan simpanan, dana, atau aset nasabah yang berada dalam tanggung jawab bank, mempunyai hak untuk mendapakan edukasi mengenai hak dan kewajiban dari bank, mempunyai hak untuk mendapat laporan tentang posisi saldo dan mutasi simpanan, dana, aset, atau kewajiban nasabah secara akurat, tepat waktu, dan dengan cara atau sarana sesuai dengan perjanjian, dan nasabah mempunyai hak untuk mendapatkan kompensasi/ ganti rugi yang timbul akibat kesalahan dan/atau kelalaian, pengurus, pegawai bank dan/atau pihak ketiga yang bekerja untuk kepentingan bank.

Perlindungan hukum secara represif diatur dalam Pasal 53 POJK Nomor 1 Tahun 2013 Tentang Perlindungan Konsumen Sektor Jasa Keuangan antara lain penegakkan sanksi administrasi antara lain peringatan tertulis, denda yaitu kewajiban untuk membayar sejumlah uang tertentu, pembatasan kegiatan usaha, pembekuan kegiatan 
usaha, dan pencabutan izin kegiatan usaha.

2. Pengawasan OJK Terhadap Kewajiban Kerahasiaan atas Penjualan Data Nasabah Bank Kewenangan OJK dalam pengaturan dan pengawasan jasa keuangan meliputi jasa keuangan perbankan dan non perbankan. ${ }^{11}$ Sejak 31 Desember 2013, OJK secara yuridis mempunyai kewenangan pengaturan dan pengawasan perbankan yang semula menjadi kewenangan Bank Indonesia (BI). ${ }^{12}$ Kewenangan yang dimaksud adalah kewenangan pengaturan dan pengawasan prudential atau micro prudential. ${ }^{13}$ Dengan berlakunya UU No.21 Tahun 2011 Tentang OJK (UU OJK), OJK selain mempunyai kewenangan pengawasan prudential juga pengawasan market conduct jasa keuangan. Dengan demikian di

11 Nova Asmirawati. Catatan Singkat Terhadap Undang-Undang Nomor 21 Tahun 2012 Tentang Otoritas Jasa Keuangan. Majalah Legalitas. Vol.9 No.3. 2012. Jakarta: Kementrian Hukum dan HAM RI. HIm.449-558.

12 Ahmad Solahudin. Pemisahan Kewenangan Bank Indonesia Dengan Otoritas Jasa Keuangan Dalam Pengawasan. Jurnal IUS Kajian Hukum Dan Keadilan, Vol.III No.7 April 2015, Jakarta: Mahkamah Agung RI. HIm.108-128.

${ }_{13}$ Lina Maulidiana. Fungsi Otoritas Jasa Keuangan Sebagai Lembaga Pengawas Perbankan Nasional Di Indonesia. Jurnal Keadilan Progresif. Vol.5 No.1 Maret 2014. Lampung: Program Studi Ilmu Hukum Universitas Bandar Lampung. HIm.103-120.
Indonesia

kewenangan

pengawasan prudential dan

market conduct jasa keuangan di tangan satu lembaga yaitu OJK, suatu lembaga otoritas jasa keuangan yang independen. ${ }^{14}$

Penerapan assessment

market conduct jasa keuangan di Indonesia baru dilaksanakan pada tahun 2015, dan hingga 16 Januari 2015 di Kantor OJK Pusat sudah ada 3.118 pengaduan. Menurut Kusumaningtuti S Setiono Dewan Komisioner OJK penerapan assessment market conduct akan menekan pelanggaran di industri jasa keuangan khususnya perbankan. Berkaitan dengan fakta yang ada, maka OJK harus memperkuat pengawasan market conduct. Penguatan pengawasan ini tidak hanya pada aspek peraturannya, tetapi juga kemampuan pengawas di seluruh kantor OJK dari pusat sampai daerah. Penguatan ini dimaksudkan untuk mencegah potensi kerugian pada konsumen jasa keuangan, bahkan pengawas dapat melakukan tindakan jika

14 Bismar Nasution. Struktur Regulasi Independen Otoritas Jasa Keuanga. Jurnal Hukum Dan Peradilan, Vol. 03. No.3, Nopember 2014. Jakarta: Mahkamah Agung RI. HIm.281-292. Lihat juga Wiwin Sri Rahyani. Independensi Otoritas Jasa Keuangan dalam Perspektif Undang-Undang Nomor 21 Tahun 2011 tentang Otoritas Jasa Keuangan. Majalah Legalitas. Vol.9 No.3. 2012. Jakarta: Kementrian Hukum dan HAM RI. HIm.361-372. 
1539 | Jurna I I d e a H u k u m

Vol. 5 No. 2 Oktober 2019

MagisterIImuHukum Universitas Jenderalsoedirman

terbukti ada pelanggaran

menyampaikan laporan Penilaian

khususnya kebocoran data

dan/atau informasi pribadi

nasabah ke pihak ketiga atau ke

pihak lain. Masih adanya kasus

penjualan data nasabah ke pihak

lain yang merugikan konsumen,

menunjukkan bahwa pengaturan

dan pelaksanaan pengawasan

market conduct jasa keuangan

masih ada kelemahan.

Berdasarkan hasil

penelitian diperoleh data bahwa

pengawasan market conduct

menurut POJK

No.1/POJK.07/2013 secara

keseluruhan sudah dilaksanakan

oleh Kantor OJK Pusat di

Directorat Market conduct.

Sementara OJK di wilayah Jawa

Tengah (Purwokerto, Tegal, Solo,

Semarang) baru melaksanakan

kewajiban yang harus dipatuhi

dalam POJK No.

1/POJK.07/2013, yaitu PUJK

wajib untuk melaksanakan fungsi

edukasi dan melayani pengaduan

konsumen. Secara berkala, PUJK

perbankan di wilayah Jawa

Tengah telah menyampaikan

laporan rencana dan pelaksanaan

edukasi, serta laporan pengaduan

konsumen. Lebih lanjut, untuk

menilai apakah PUJK telah

mengimplementasikan POJK No.

1/POJK.07/2013, OJK

mewajibkan PUJK untuk

${ }^{15}$ Sulistyandari, Noor Aziz Said, MI. Wiwik Yuni Hastuti. Penguatan PengawasanMarket Conduct Jasa Keuangan oleh OJK di Wilayah Jawa Tengah.

${ }_{17}^{16}$ Hasil wawancara dengan OJK. op.cit.

17 lbid. tahun sekali pada Bulan Juni, maksimal pada tanggal 30 September. ${ }^{15}$

Pada pengawasan Market Conduct, OJK melakukan pengawasan pada perilaku PUJK dalam keseluruhan product life cycle, mulai dari desain produk, pemasaran, hingga penanganan pengaduan. $^{16}$ OJK dalam melakukan pengawasan market conduct pada bank-bank di antaranya adalah melalui thematic surveillance, pemantauan lapangan, dan self assessment. ${ }^{17}$ Selama ini OJK melakukan pengawasan Market Conduct, pada bank-bank yang ada sesuai dengan kewenangan OJK sebagaimana yang tertuang di dalam Pasal 28-31 UU Nomor 21 Tahun 2011 tentang Otoritas Jasa Keuangan. Pasal-pasal tersebut berhubungan dengan kewajiban bank untuk melakukam perlindungan hukum kepada nasabah, dan masih menurut pengakuan pihak OJK, selama ini OJK sudah melakukan pengawasan market conduct dan berjalan sesuai peraturan yang 
ada dan sesuai dengan ketentuan yang berlaku. ${ }^{18}$

Pengawasan OJK tersebut adalah memastikan bank atau PUJK melaksanakan kewajiban yang harus dipatuhi dalam POJK No. 1/POJK.07/2013, yaitu PUJK wajib untuk melaksanakan fungsi edukasi dan melayani pengaduan konsumen. Secara berkala, PUJK perbankan di wilayah Jawa Tengah telah menyampaikan laporan rencana dan pelaksanaan edukasi, serta laporan pengaduan konsumen. Lebih lanjut, untuk menilai apakah PUJK telah mengimplementasikan POJK No. 1/POJK.07/2013, maka OJK mewajibkan PUJK untuk menyampaikan laporan Penilaian Mandiri atau Self Asessment satu tahun sekali pada Bulan Juni, maksimal pada tanggal 30 September. ${ }^{19}$

Berdasarkan hasil penelitian diperoleh data bahwa sesuai dengan Pasal 35 ayat 1 POJK No. 1/POJK.07/2013, PUJK wajib segera menindaklanjuti dan menyelesaikan pengaduan paling lambat 20 hari kerja setelah tanggal penerimaan pengaduan. Apabila masih terdapat PUJK yang belum dapat memenuhi kewajiban penyelesaian pengaduan konsumen maksimal 20 hari kerja, OJK selalu menghimbau agar PUJK segera menindaklanjuti pengaduan konsumen sesuai dengan ketentuan (maksimal 20 hari kerja). ${ }^{20}$

Apabila dalam kasus tertentu PUJK membutuhkan tambahan waktu, sesuai dengan Pasal 35 ayat 2, PUJK dapat memperpanjang jangka waktu sampai dengan paling lama 20 hari kerja berikutnya dan wajib disampaikan secara tertulis kepada konsumen. Oleh karena itu pengawasan market conduct oleh OJK selama ini diakui sudah berjalan sesuai harapan semua pihak, karena OJK sudah melaksanakan pengawasan market conduct di samping pengawasan prudential agar selain memiliki industri jasa keuangan yang kuat, hubungan antara industri dengan konsumen juga baik, sehingga tercipta stabilitas di sektor jasa keuangan. 21

Apabila pengawasan market conduct yang dilakukan oleh OJK sudah efektif, sudah sesuai dengan peraturan yang ada maka selayaknyalah pengawasan tesebut dapat
${ }^{18}$ Ibid.

${ }^{19}$ Ibid. 
1541 | Jurna I I d e a H u k u m

Vol. 5 No. 2 Oktober 2019

MagisterIImuHukum Universitas Jenderalsoedirman

melindungi data nasabah, sebagaimana yang telah diatur secara rinci dalam SEOJK Nomor 14 Tahun 2014 Tentang Kerahasiaan dan Keamanan Data dan/atau Informasi Pribadi Konsumen. Dengan demikian akan dapat dikatakan bila pengawasan market conduct yang telah dilakukan oleh OJK dapat menjaga rahasia perbankan sepenuhnya. Kerahasiaan dan keamanan data nasabah tidak hanya dibebankan oleh OJK semata, diperlukan juga awareness dari konsumen untuk ikut menjaga kerahasiaan data perbankannya sendiri. ${ }^{22}$

Dari uraian di atas diperoleh gambaran bahwa pengawasan terhadap market conduct jasa keuangan perbankan oleh OJK, secara keseluruhan sudah dilaksanakan oleh Kantor OJK Pusat di Directorat Market conduct, namun untuk OJK di wilayah daerah seperti kabupaten/kota belum sepenuhnya melaksanakan pengawasan PUJK dan baru melaksanakan kewajiban yang harus dipatuhi dalam POJK No. 1/POJK.07/2013, yaitu pengawasan terhadap kewajiban PUJK untuk melaksanakan fungsi edukasi dan pelayanan pengaduan konsumen. Berdasarkan fakta ini maka OJK belum melakukan pengawasan pada PUJK terkait perilaku penyimpangan dan penyalahgunaan kekuasaan dalam penyertaan informasi. Dengan demikian dapat diperoleh gambaran bahwa pengawasan OJK secara market conduct belum maksimal karena belum dilaksanakan sepenuhnya oleh OJK di daerah sehingga berdasarkan fakta ini juga dapat dikatakan bila pengawasan OJK terhadap kewajiban kerahasiaan nasabah oleh bank yang berdampak pada perlindungan konsumen jasa keuangan juga belum maksimal karena belum semua nasabah di daerah-daerah kerahasiaan data pribadinya aman dari perilaku penyimpangan dan penyalahgunaan kekuasaan PUJK yang berarti belum mendapat perlindungan hukum yang maksimal dari OJK. Hal ini juga dikarenakan masih ada beberapa kewajiban yang tujuannya memberikan perlindungan konsumen belum dilaksanakan, utamanya adalah pengawasan OJK pada PUJK terkait perilaku penyimpangan dan penyalahgunaan kekuasaan dalam penyertaan informasi. 
Terkait dengan kerahasiaan data nasabah bank agar tidak terjadi kebocoran informasi, maka OJK perlu meningkatkan framework pengawasan market conduct dengan memperkuat kemampuan tenaga pengawas khusus di market conduct di seluruh cabang di daerah. Kenyataan belum dilakukannya framework pengawasan market conduct di seluruh cabang OJK di daerah, dapat menandakan kurangnya komitmen OJK dalam melakukan pengawasan market conduct pada pelaku jasa keuangan khususnya di daerah.

\section{E. Simpulan dan Saran}

\section{Simpulan}

$$
\text { Perlindungan hukum }
$$

nasabah atas penjualan data nasabah bank dapat dikatakan bahwa perlindungan hukum tersebut sudah diatur dengan adanya SEOJK Nomor 14 Tahun 2014 Tentang Kerahasiaan dan Keamanan Data dan/atau Informasi Pribadi Konsumen, dan POJK Nomor 1 Tahun 2013 Tentang Perlindungan Konsumen Sektor Jasa Keuangan. Perlindungan nasabah khususnya terhadap data nasabah dengan peraturan perundangan OJK yang ada, sudah diatur dari dua sisi, yaitu perlindungan hukum secara preventif dan perlindungan hukum secara represif.

Pelaksanaan pengawasan

OJK terhadap kewajiban kerahasiaan atas penjualan data nasabah bank dalam hal ini dilihat dari sisi pengawasan market conduct jasa keuangan perbankan oleh OJK, secara keseluruhan sudah dilaksanakan oleh Kantor OJK, namun belum dilaksanakan sepenuhnya oleh OJK di wilayah/daerah seperti OJK kabupaten/kota. OJK di wilayah/daerah seperti OJK kabupaten/kota baru melaksanakan pengawasan market conduct sebatas pengawasan kepada kewajiban PUJK untuk melakukan edukasi dan pelayanan pengaduan konsumen.

\section{Saran}

a. Pihak bank sebaiknya melakukan pengawasan dan pengendalian internal agar tidak terjadi adanya pegawai yang melakukan penyalahgunaan wewenang atau penjualan data nasabah.

b. Bank sebaiknya menerapkan pemberian sanksi kepada pegawai bank yang menyalahgunakan wewenang dalam penggunaan data informasi nasabah bank. 
1543 | Jurna I I d e a H u k u m

Vol. $5 \mathrm{No} .2$ Oktober 2019

MagisterIImuHukum Universitas Jenderalsoedirman

c. Pihak bank sebaiknya melakukan edukasi kepada masyarakat atau nasabah agar pro aktif dengan melakukan pengaduan bila ada pelanggaran dan tidak mudah memberikan data atau informasi perbankan nya pada pihak lain.

d. OJK Pusat sebaiknya segera memerintahkan OJK di daerah untuk melakukan pengawasan market conduct pada PUJK terkait perilaku penyimpangan dan penyalahgunaan kekuasaan dalam penyertaan informasi.

e. OJK sebaiknya meningkatkan pengawasan market conduct pada PUJK dan edukasi baik pada PUJK maupun konsumen terkait perlindungan hukum nasabah dan kerahasiaan data nasabah.

\section{DAFTAR PUSTAKA}

Amiruddin dan Zainal Asikin. 2006. Pengantar Metode Penelitian Hukum. Jakarta: PT. Raja Grafindo Persada.

Djumhana, Muhamad. 1996. Rahasia Bank (Ketentuan dan Penerapannya di Indonesia). Bandung: PT. Citra Aditya Bakti.

Marzuki, Peter Muhamad. 2008. Penelitian Hukum (Cetakan ke 2). Jakarta: Kencana.

Hanadi, Saryono. 2008. Metodologi Penulisan dan Penelitian Hukum. Purwokerto: Universitas Jenderal Soedirman.
Subekti, Trusto. 2009. Metodologi Penulisan dan Penelitian Hukum. Purwokerto: Universitas Jenderal Soedirman.

Solahudin, Ahmad. Pemisahan Kewenangan Bank Indonesia Dengan Otoritas Jasa Keuangan Dalam Pengawasan. Jurnal IUS Kajian Hukum Dan Keadilan, Vol.III No.7 April 2015, Jakarta: Mahkamah Agung RI.

Nasution, Bismar. Struktur Regulasi Independen Otoritas Jasa Keuanga. Jurnal Hukum Dan Peradilan, Vol. 03. No.3, Nopember 2014. Jakarta: Mahkamah Agung RI. HIm.281292. Lihat juga Wiwin Sri Rahyani. Independensi Otoritas Jasa Keuangan dalam Perspektif Undang-Undang Nomor 21 Tahun 2011 tentang Otoritas Jasa Keuangan. Majalah Legalitas. Vol.9 No.3. 2012. Jakarta: Kementrian Hukum dan HAM RI.

Manalu, Juli Etha, Agne Yasa Damanik, \& Andry Winanto. 2017. Kasus Jual-Beli Informasi Nasabah : Lindungi Data Pribadi!. Tribun Jateng. 22 Agustus 2017.

Maulidiana, Lina. Fungsi Otoritas Jasa Keuangan Sebagai Lembaga Pengawas Perbankan Nasional Di Indonesia. Jurnal Keadilan Progresif. Vol.5 No.1 Maret 2014. Lampung: Program Studi IImu Hukum Universitas Bandar Lampung.

Hadad, Muliaman D. 2014. OJK Perkuat Perlindungan Konsumen Melalui Pengawasan Market Conduct. Siaran Pers: No. SP25/DKNS/OJK/9/2014.

Asmirawati, Nova. Catatan Singkat Terhadap Undang-Undang Nomor 21 Tahun 2012 Tentang Otoritas Jasa Keuangan. Majalah Legalitas. Vol.9 No.3. 2012. Jakarta: Kementrian Hukum dan HAM RI.

Sulistyandari, Noor Aziz Said, MI. Wiwik Yuni Hastuti. Penguatan PengawasanMarket Conduct Jasa Keuangan oleh OJK di Wilayah Jawa Tengah. 